\title{
The Syntax of Assertion and Presupposition*
}

\author{
Kajsa Djärv \\ UPenn/Universität Konstanz.
}

\begin{abstract}
This paper addresses the question of how assertion and presupposition are reflected in the grammar. Since Kiparsky \& Kiparsky 1970 and Hooper \& Thompson 1973, it's often been suggested that these notions provide the semanticpragmatic underpinning for a range of complementation patterns, including the licensing of so-called Main Clause Phenomena [MCP]. This paper presents a new large-scale experimental study, investigating the lexical and semantic-pragmatic licensing conditions of four types of MCP (Verb Second [V2], topicalization, speech act adverbs, and scene setting adverbs) in English, Swedish, and German. The central contribution of this paper is demonstrating what precise dimensions of assertion and presupposition are reflected in the grammar: for embedded V2, what matters is the discourse status of the embedded proposition as new vs. Given (in the sense of Schwarzschild 1999); a dimension which cross-cuts both factive and non-factive verbs. The other MCP investigated show no sensitivity to either of the lexical or pragmatic factors investigated. We further show that Givenness is not reflected in a (null) DP-layer, contrary to previous claims.
\end{abstract}

Keywords: attitude reports, assertion, factivity, presupposition, syntax-pragmatics interface, main clause phenomena, Germanic verb second, topicalization.

\section{Introduction}

[This paper represents a condensed version of Djärv 2019b: Ch. 2 and 3.] This paper addresses the question of how assertion and presupposition are reflected in the syntax of propositional attitude reports (e.g. Mary believes that Bill is moving to Canada). We present selected results from a new large-scale experimental study investigating the lexical and semantic-pragmatic licensing conditions of four types of Main Clause Phenomena [MCP] (Verb Second [V2], topicalization, speech act adverbs, and scene setting adverbs) in English, Swedish, and German.

* Special thanks to Florian Schwarz and Jérémy Zehr for much helpful feedback and discussion. Thanks also to Luke Adamson, Spencer Caplan, Amy Goodwin Davies, Alex Göbel, Astrid Gößwein, Melly Hobich, Keir Moulton, Julie Anne Legate, Julian Sahasrabudhe, Meredith Tamminga, Muffy Siegel, and Becky Woods, for helpful input. Thanks also to audiences at SALT29 at UCLA, LAGB 2019 at Queen Mary, ILST at UPenn, and the University of Huddersfield. This work was supported by the Teece Foundation and Penn's ILST (Integrated Language Science and Technology) initiative.

C2019 Djärv 
The main finding of the experiment is that $\mathrm{V} 2$ tracks the availability of $\mathrm{p}$ as discourse new information (as contrasted with the status of $\mathrm{p}$ as Given, in the sense of Schwarzschild 1999) - a dimension which cross-cuts both factive and non-factive verbs. The interpretation of $\mathrm{p}$ as new vs. Given is found to depend closely on the type of predicate; however, interactions with the polarity of the matrix clause speak against a selection-based account. The other MCP investigated, on the other hand, are found to be sensitive to neither type of lexical or pragmatic factor investigated; showing us that MCP encompass a less homogeneous set of constructions than generally assumed. We moreover show that Givenness does not imply that the embedded clause is underlyingly a DP, as per previous proposals (e.g. Haegeman 2014; Kastner 2015; following Kiparsky \& Kiparsky 1970).

\subsection{Overview of the paper}

Section 1.2 looks at previous approaches to MCP, finding a highly complex theoretical and empirical landscape, with substantial disagreement not just on the theoretical side, but also in terms of what the empirical facts actually are. The main open questions are discussed in Section 1.3. This discussion leaves us with the conclusion that without comparative data from a larger number of speakers and a wider range of verbs, MCP, and languages, further theoretical progress is difficult. Section 2 presents the current experiment, addressing these open questions. Section 3 discusses the analytical consequences of the present findings, showing further that Givenness is not semantically encoded in a null D-layer. We end on a note on the implications of the current findings for the theory of factivity.

\subsection{Background}

Since Hooper \& Thompson 1973, it has often been proposed that ASSERTION provides the semantic-pragmatic underpinning of a range of complementation patterns, including the licensing of so-called Main Clause Phenomena, for instance:

a. Cats, I really like.

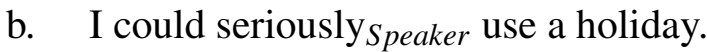

c. Han gillar inte (*gillar) skräckfilm.

he likes not likes horror.film

'He doesn't like horror movies.'

Topicalization

Speech Act Adverbs

V2 (Swedish)

A central question in this area concerns the role of the embedding verb: do certain types of verbs (e.g. say, think) make available the type of pragmatics that licenses these complements (e.g. Woods 2016; Caplan \& Djärv 2019), or is selection involved (e.g. Wiklund, Bentzen, Hrafnbjargarson \& Hróarsdóttir 2009; Kastner 2015)? A 
related question is what precise dimension of the classically multifaceted notion of assertion is relevant to the syntax of clausal embedding. Following Stalnaker (1974), it is generally assumed that to assert a proposition $\mathrm{p}$, it is required that:

a. The speaker is committed to $\mathrm{p}$;

b. The speaker is attempting to add $\mathrm{p}$ to the Common Ground (the set of propositions mutually taken to be true by the discourse participants).

This makes the prediction that factive attitude reports, involving predicates like know, discover, realize, resent, appreciate, and regret, should not license MCP — given the standard assumption (since Stalnaker 1974, 1978; Heim 1982, 1983) that factive predicates presuppose the embedded proposition $\mathrm{p}$; i.e. require that $\mathrm{p}$ is Common Ground; in direct conflict with (2-b). In spite of this, it has often been claimed (following Hooper \& Thompson 1973), that at least some factives (specifically, cognitive factives like discover and find out) do allow MCP in their complements.

a. The scout discovered that beyond the next hill stood a large fortress.

b. I found out that never before had he had to borrow money.

Circumventing the issue presented by the factives, a number of researchers have proposed that the dimension of assertion relevant to the licensing of MCP is only that in (2-a): that the speaker (or attitude holder) is committed to $\mathrm{p}$ (e.g. Truckenbrodt 2006; Wiklund 2010; Julien 2015; Woods 2016). That is, while (2-b) is at odds with factivity, speaker commitment to $\mathrm{p}$ is a defining feature of factive predicates. ${ }^{1}$

In contrast to this position, other authors have argued that the dimension of assertion relevant to MCP is the discourse status of $\mathrm{p}$, as in (2-b). This theoretical position is motivated by the empirical assumption that all factive verbs disallow MCP (5). Rather than taking MCP to be licensed by assertion, these authors, following Kiparsky \& Kiparsky (1970), take MCP to be blocked by presupposition.

$$
\begin{aligned}
& \text { a. *John \{regrets, resents }\} \text { that [this book], Mary read. Emo.Factive } \\
& \text { (Maki, Kaiser \& Ochi 1999: 3, Basse 2008: 58, Haegeman \& Ürögdi } \\
& \text { 2010: 112-113, 122, De Cuba \& Ürögdi 2010: 43, Haegeman 2012: } \\
& \text { 257, Kastner 2015: 3), De Cuba 2017: 21) }
\end{aligned}
$$

1 Specifically, the speaker's commitment to $\mathrm{p}$ (like other presuppositions) tends to project from the scope of embedding operators, such as modals and negation (4). This is unlike their asserted content (here, the emotive state of the attitude holder), which does get targeted by such operators:

$$
\begin{aligned}
& \text { a. Anna is sad that }[P \text { Lisa got the job }] \text {. } \\
& \text { b. Anna isn't sad that }[P \text { Lisa got the job]. }
\end{aligned}
$$

$$
\begin{aligned}
& \leadsto \text { Anna } \odot \mathrm{p} ; \leadsto \mathrm{p} \\
& \gg \text { Anna } \odot \mathrm{p} ; \sim \mathrm{p}
\end{aligned}
$$


The Syntax of Assertion and Presupposition

b. *Mary realizes that [this book], John read. Cog.Factive (Hegarty 1992: 52, fn. 19; Maki et al. 1999: 3; De Cuba 2017: 21, Haegeman 2012: 257)

Sharing elements of both of these proposals, is the position taken by Caplan \& Djärv (2019), arguing on the basis of Swedish corpus data that embedded V2 is licensed by discourse novelty, in line with the latter type of approach. They share with the former approach, however, the empirical position that the cognitive and emotive factives vary with regard to the availability of embedded V2 (cognitives allow for embedded V2, emotives do not; a position motivated by the distribution of V2 in the corpus). They argue, based on the contrast in (7) that, unlike the emotives, the cognitive factives allow $\mathrm{p}$ to be presented as discourse new information: ${ }^{2}$

(7) [Uttered out of the blue:] Guess what - (Caplan \& Djärv 2019: 21)

a. John \{told me, thinks, discovered $\}$ that $\left[{ }_{P}\right.$ Bill and Anna broke up].

b. \#John appreciates that $[P$ Bill and Anna broke up].

The key piece of Caplan \& Djärv's (2019) argument is that the availability of discourse new information varies with the polarity of the embedding predicate:

Guess what - (Caplan \& Djärv 2019: 23)

\#John \{didn't tell me, doesn't think $\}$ that $[P$ Bill and Anna broke up].

This makes the prediction that verbs like say, tell and think, which ordinarily allow for both embedded V2 and the introduction of discourse new information, should, under negation, show significantly lower rates of embedded V2. This prediction which was borne out in the corpus data. The findings of Caplan \& Djärv (2019) shows us two important things: that embedded V2 in Swedish is not due to selection (contra e.g. Wiklund et al. 2009); and that factivity per se is not relevant to V2 (in line with previous work on Scandinavian V2). Rather, their results suggest that V2 is licensed in contexts where $\mathrm{p}$ constitutes discourse new information; a pragmatic property of an utterance in context, which is constrained, but not determined, by the matrix verb. In Section 2, we present experimental results from German, supporting Caplan \& Djärv's (2019) conjecture that (a) embedded V2 is licensed by discourse

2 Note that a similar point was made by Simons (2007) in the context of Q\&A pairs like (6) - showing that cognitive and emotive factives differ with respect to the at-issue status of $\mathrm{p}$.

Where is John? / I \{think, believe, found out, \#resent\} that [P he's in New York].

Based on distributional data, Jensen \& Christensen (2013) argued that V2 is licensed by the at-issue status of p. Experimental data by Djärv, Heycock \& Rohde (2017), manipulating the at-issue status of $\mathrm{p}$, replicated the distributional pattern, but found no effect of the at-issue status of $\mathrm{p}$ on embedded V2. 
novelty, and (b) that cognitive factives (across the three languages investigated) have a salient a reading whereby $\mathrm{p}$ is understood as discourse new information. We also address some further open issues regarding the licensing of MCP more broadly, which we turn to next.

\subsection{Open questions}

A first question is whether the claim that embedded V2 is licensed by discourse novelty can be extended to other MCP (and embedded V2) in a wider range of languages. While the prediction that all factives should disallow MCP seems clearly wrong when applied to Swedish embedded V2, it is less clear that the same should hold for instance for English topicalization. While (3) suggests such an alignment, (5) on the other hand, indicates that all factives disallow embedded topicalization. Adding further to this complicated empirical picture, is the judgement in (9), suggesting that English topicalization is in fact available also under the emotive factives.

(9) Bianchi \& Frascarelli (2009: 69)

I am glad that this unrewarding job, she has finally decided to give up.

While these judgements appear contradictory, it is possible that conflicting data does in fact reflect variation along various dimensions: First, there might be variation among speakers. Second, there might be more fine-grained points of variation among different predicates of the 'same type', and between their counterparts across languages. Finally, as these judgements are quite subtle, conflicting judgement might be due to a lack of control for elements of the context.

Moreover, regarding embedded V2, the observation that embedded V2 is sensitive to negation has also been used, for instance by Truckenbrodt (2006), to support the position that embedded V2 is licensed by commitment to p: the idea being that negation cancels the relevant commitment-dimension of verbs like say and think.

(10) German (Truckenbrodt 2006: 278, 295, 297)

a. Hans glaubt, Peter hat gewonnen.

Hans thinks, Peter has won.

'Hans thinks that Peter won.'

b. *Hans \{glaubt nicht, bezweifelt $\}$, Peter hat gewonnen.

Hans \{thinks not, doubts\}, Peter has won.

'Hans \{doesn't think, doubts \} that Peter won.'

Thus, looking only at predicates like say, think and doubt, the predictions of ASSERTION-as-discourse novelty and ASSERTION-as-speaker commitment are difficult to tease apart. Adding a further dimension of complication, is the claim that Swedish 
and German embedded V2 differ with regard to their pragmatic licensing conditions; specifically, regarding whether speaker or attitude holder commitment (or both) are relevant to V2 (Woods 2016). To test the predictions of the available accounts, and to ensure a solid empirical foundation for our theory, we need to look at a wider range of embedding contexts. (11)-(12) summarizes the key open questions:

What dimension of assertion is relevant to the licensing of MCP:

a. Speaker commitment to p? (Wiklund 2010, Scandinavian V2 and speech act adverbs; Woods 2016, German V2)

b. Attitude holder (or speaker) commitment to p? (Truckenbrodt 2006; German V2; Julien 2015, Scandinavian V2; Woods 2016, speech act adverbs; Woods 2016, Scandinavian V2)

c. The discourse status of $\mathrm{p}$ as new information? (Caplan \& Djärv 2019, Swedish V2)

\section{(12) Is there variation:}

a. Across languages (e.g. Mainland Scandinavian, German, English)?

b. Between different MCP (e.g. embedded V2, topicalization, etc.)?

c. Among speakers?

Regarding the role of the embedding predicate, it is worth noting that many of the accounts discussed here use distributional data - observations about the availability of MCP under different predicate types - as the basis for claims about the pragmatic licensing conditions of different MCP. Using distribution as a 'proxy' for discourse pragmatics in not a problem in itself. However, it becomes problematic here as a basis for analysis, given that: (a) analytical claims are often based on sparsely selected observations from a small set of verbs and sentences (e.g. say, know, and regret); and (b) in a lot of these cases, different accounts make the same predictions, e.g. (10). Moreover, while pragmatic judgements are generally clear for contrasts like think vs. doubt, it is less clear what range of pragmatic properties are associated with the wider range of verbs taken to represent the various lexical classes assumed to be relevant to MCP-licensing. For instance, while believe clearly implies commitment to $\mathrm{p}$, it is less clear what to expect for other non-factive doxastic predicates like assume, guess, imagine (cf. Truckenbrodt 2006; Julien 2015).

Adopting a different perspective, other authors have argued that the type of complement that allows MCP is selected for only by particular verbs. Following Hooper \& Thompson (1973), Wiklund et al. (2009) propose that the verbs in (13-a), but not those in (13-b) select a ForceP, in the sense of Rizzi (1997), which licenses $\mathrm{V}$-to-C movement, topicalization, etc. 
Following Kiparsky \& Kiparsky (1970), on the other hand, Kastner 2015 argues that the verbs in (14-b) select a presuppositional definite determiner, which does not license Topic and Focus projections, unlike (14-a).
a. Speech act, Doxastic non-factives
$\checkmark \mathrm{MCP}$
b. Response verbs, Emotive factives, Doxastic factives
$X \mathrm{MCP}$

To address the range of open questions identified above, the current experiment investigated four MCP, across three languages. This allowed us to test for variation in a given language across different MCP, as well as for variation for a particular type of MCP across languages.

\section{Experiment}

The key innovation of this study is to collect independent, empirically motivated measures of the various notions of assertion proposed to be relevant to MCP-licensing (speaker and attitude holder commitment to $\mathrm{p}$, and the status of $\mathrm{p}$ as discourse new information), for a range of sentences involving both factive and non-factive verbs. We then collected - for the exact same sentences- judgements of acceptability for the various MCP. This method allowed us to tease apart the lexical and pragmatic accounts, as it gave us an estimate of the pragmatics of the sentence, independent of the identity and class of the embedding verb (and one which is based on naive speakers' intuitions, rather than the possibly theoretically informed judgements of researchers. Moreover, this method directly tests the assumption that verbs can be grouped into classes, based on their pragmatic and grammatical properties).

\subsection{Language and MCP variations}

The experiment investigated four MCP in three languages, as shown in Table 1. Each language and MCP-condition was varied between participants.

All experimental materials, including data sources, instructions, scripts used by Ibex, etc, are available through the Open Science Foundation: https://osf.io/nsm89/ (Djärv 2019a). For further details of the experimental methods and results, see Djärv 2019b: Ch. 3.2..

In addition to the MCP-manipulations, each item also occurred in an unmarked condition, providing a ceiling for the acceptability of each of the sentences used, independently of any MCP-manipulation. This is important, since while the consensus among linguists is that a sentence like Mary resents that Lisa got the job is grammatical, this does not mean that naive participants in an experiment will judge such 
The Syntax of Assertion and Presupposition

\begin{tabular}{llll}
\hline Speech act adverbs & English & German & Swedish \\
Topicalization (Object DP) & English & - & - \\
Scene Setting Adverbs & English & - & - \\
Embedded V2 & - & German & Swedish \\
Unmarked Control Sentences & English & German & Swedish
\end{tabular}

Table 1 Languages and MCP varied in the experiment.

sentences to be as acceptable or natural as Mary thinks that Lisa got the job. Thus, including unmarked versions of each sentence provides a baseline relative to which we can measure the effect of the MCP variation, independently of the effect of the embedding predicate, or the particular choice of embedded clause (see Section 2.6). In both Swedish and German, these sentences had the finite verb in-situ. In Swedish, which is SVO, V2 is diagnosed via the order of the finite verb and negation, as in (1-c). In German, an SOV-language, the V2-manipulation is achieved by varying the order of the finite verb with respect to its complement. The speech act adverbs (1-b) used were honestly/seriously in English, ehrlich gesagt/offen gestanden in German, and ärligt talat/allvarligt talat in Swedish. Topicalization involved fronting of an object DP (1-a), and the scene setting adverbs involved a high temporal/situational adverb such as last year or in college.

The choice of constructions investigated across these different languages was partially constrained by practical considerations. To start, English does not have V2, which makes it impossible to investigate. Second, while both Swedish and German allow for topicalization of a DP in object position and high scene setting adverbs, such sentences are obligatorily V2, thus making it difficult to disentangle the impact of toplicalization from that of $\mathrm{V}$-to-C movement. The current design, illustrated in Table 1, nevertheless has the advantage of allowing us to compare both the distribution and licensing conditions of particular MCP across different languages (V2 in German and Swedish, and speech act adverbs in English, German, and Swedish), as well as the distribution and licensing conditions of different MCP within each language. This allowed us to test for variation along both of these lines. To achieve the language/MCP manipulation, the embedded clauses were first constructed, in the unmarked condition in English, and subsequently translated to Swedish and German. The unmarked stimuli were then varied, in each language, by MCP-type. The materials were then checked for naturalness and typos, etc, by native speakers of English, German and Swedish, respectively. ${ }^{3}$

3 In the case of the original English items, a set of small pilot studies were run online (on Prolific.ac) to minimize the variation in the unmarked items; these were not included in the analysis. In the case 


\subsection{Pragmatic and lexical variations}

To address the issues regarding the role of the embedding predicate discussed in Section 1.2, the experiment capitalized on the observation that the predictions of the various, often closely related, accounts come apart when we look at a wider set of predicates than typically considered. As a case in point, consider the negative response predicates (e.g. doubt, deny). On an account based on discourse-novelty, we would expect these to disallow embedded V2, regardless of their polarity. However, Wiklund (2010) claims that embedded V2 improves when a verb like doubt is negated, apparently in line with a commitment-based assertion account.

Swedish (Wiklund 2010: 83)

a. ?Jag tvivlar inte på att den boken köper du.

I doubt not on that that book buy you

'I don't doubt that you'll buy that book.'

b. *Jag tvivlar på att den boken köper du.

I doubt on that that book buy you

'I doubt that you'll buy that book.'

To this effect, the experiment looked at 20 verbs from the five verb classes in $(13) /(14)$ (4 verbs per class), each verb varied by polarity: see Table 2 in the Appendix. To the extent possible, the closest counterparts were chosen for each verb in the different language variations (aiming for similarities in entailments, presuppositions, and conventional use). Each verb occurred in exactly two items. The critical items consisted of a complex sentence (such as Mary believes that Bill moved to Canada), which occurred in two conditions, corresponding to the presence or absence of matrix negation (e.g. believed vs. didn't believe). This added up to 40 critical items. To avoid effects specific to particular combinations of negation and material in the embedded clause, the experiment used a Latin square design with two subject groups, so that each the participants saw each verb twice, once with matrix negation, and once without, with different embedded content.

To control for any contextual effects, the experimental items were all presented in the same discourse context. The English study was carried out in two discourse conditions, varied between participants: one designed to promote an interpretation of $\mathrm{p}$ a discourse new information (MAXNEWNESS), and one designed to promote an interpretation of $\mathrm{p}$ as contrastive (MAXCONTRAST). Figure 5 and Figure 6 in

of Swedish, the translator was the author. The German stimuli were translated by Astrid Gößwein at Goethe-Universität Frankfurt and Lukas Stein at the University of Tübingen, and extensively checked by Florian Schwarz at the University of Pennsylvania. Melanie Hobich at Goethe-Universität Frankfurt, and Alex Göbel at the University of Massachusetts at Amherst also contributed helpful input and feedback to the German translations. 
the Appendix illustrate. This was partially to test the 'pragmatic flexibility' of the different predicates, given the discourse context. The MAXCONTRAST condition also served the purpose of promoting the licensing of English topicalization, which is known to be contrastive. The MAXNEWNESS context was designed to promote a discourse new reading of $\mathrm{p}$, as proposed to be relevant to V2. This allowed us to better tease apart any effects due to the predicate from the context manipulation. Due to limitations of resources (time, funds, participants), the Swedish and German experiments were only run in the MAXNEWNESS condition.

\subsection{Controls and fillers}

In addition to the unmarked controls (Section 2.1), the acceptability studies included three further controls: 8 unembedded MCP sentences, as in (1), providing a baseline for each type of MCP, independently of any embedding; 8 unembedded and unmarked items, providing an overall ceiling for acceptability (e.g. Bill moved to Canada). ${ }^{4}$; and 16 sentences involving 8 attitude verbs taking 'fact that p' complements, providing a floor for acceptability ${ }^{5}$ (e.g. Lisa thought the fact that Bill moved to Canada). The pragmatic inference tasks included separate fillers and controls, relativized to the three different tasks.

\subsection{Task}

The participants' task was to rate the acceptability (naturalness) of the target sentences on a 9-point Likert Scale with the endpoints marked. (See Figures 7-10 in the Appendix.) For an independent and empirically motivated measure of the pragmatic dimensions of interest, the 40 critical items were tested in the unmarked control version for: speaker commitment to $\mathrm{p}$, attitude holder commitment to $\mathrm{p}$, and the likelihood that $\mathrm{p}$ is discourse new. ${ }^{6}$ As with the acceptability ratings, these judgements were given on the same type of Likert Scale. The type of judgement

4 In German and Swedish, both of these had V2-order.

5 These items had all been confirmed by several native speakers to be generally ill-formed with the fact that $p$ complements. The idea was that these items would be close in acceptability to the degraded MCP-variations; both involving relatively weak ill-formedness, thus preventing the participants to give the degraded MCP items ceiling ratings, by comparison- a potential worry if strong syntactic violations had been used as floor controls.

6 The reason for using the unmarked sentences here was to get an estimate of the pragmatic constraints placed on each target sentence, given its specific lexical content, including the attitude holder, the type of embedding verb, the presence or absence of matrix negation, and the content of the embedded clause. If, given these different factors, the sentence got high scores on any of the pragmatic dimensions, and that dimension is in fact relevant to the licensing of a given type of MCP, then we predict that specific MCP variation to receive high acceptability ratings, for that particular sentence. 
was varied between participants, so that each participant only gave one type of judgement.

\subsection{Participants \& implementation}

A total of 1,272 participants took part in the study. 117 participants were excluded from analysis, leaving a total of 1,155 participants in the final data set. 845 English speaking participants took part in the study; these were either recruited on Prolific.ac, a crowd-sourcing tool for recruiting participants to participate in scientific studies online, or through Penn's Psychology department's subject pool. Participants recruited on Prolific were paid at a rate of 6.80 USD per hour for their participation, whereas the latter group took the experiment for course credit. 285 German speaking participated in the study; all recruited on Prolific and paid 6.80 USD per hour. 142 Swedish speakers participated in the study. Due to there being a limited number of Swedish speakers on Prolific, the participants were recruited both through Prolific (and paid 6.80 USD per hour) and through various personal and professional contacts of the author (voluntary participation). ${ }^{7}$ The total number of participants for each between-subject condition, before and after exclusion, is listed in Table 3 in the Appendix. The experiment was implemented using PennController (Zehr \& Schwarz 2018) on http://spellout.net/ibexfarm/. Thus, regardless of the recruitment method, all participants were given a link to take the experiment online. The study took approximately 15 minutes to complete.

\subsection{Data trimming}

Data trimming was done in three steps. First, participants' responses were transformed into z-scores (using the ave() and scale() functions in R), in order to eliminate potential scale bias and to normalize the data, thus allowing us to run parametric tests, which are generally more powerful than non-parametric tests (see Schütze \& Sprouse 2014: 18). Secondly, participants were excluded from analysis if they were unable to sufficiently distinguish between the floor and ceiling control conditions. Finally, to account for any variation across conditions not due to the MCP-manipulation, the data was residualized. ${ }^{8}$ This involved running a simple linear model, predicting the responses for each type of MCP from those in the unmarked control condition (recall that the only difference between these conditions was the MCP manipulation). The residuals from the model (i.e. any variation not

7 This number was based on a power simulation using the simr package in R. Unfortunately, because of issues with the unmarked controls, the Swedish MCP-results are omitted from the current discussion; see Djärv 2019b: Sec. 3.2.4.3 for details.

8 Thanks to Meredith Tamminga for this suggestion. 
The Syntax of Assertion and Presupposition
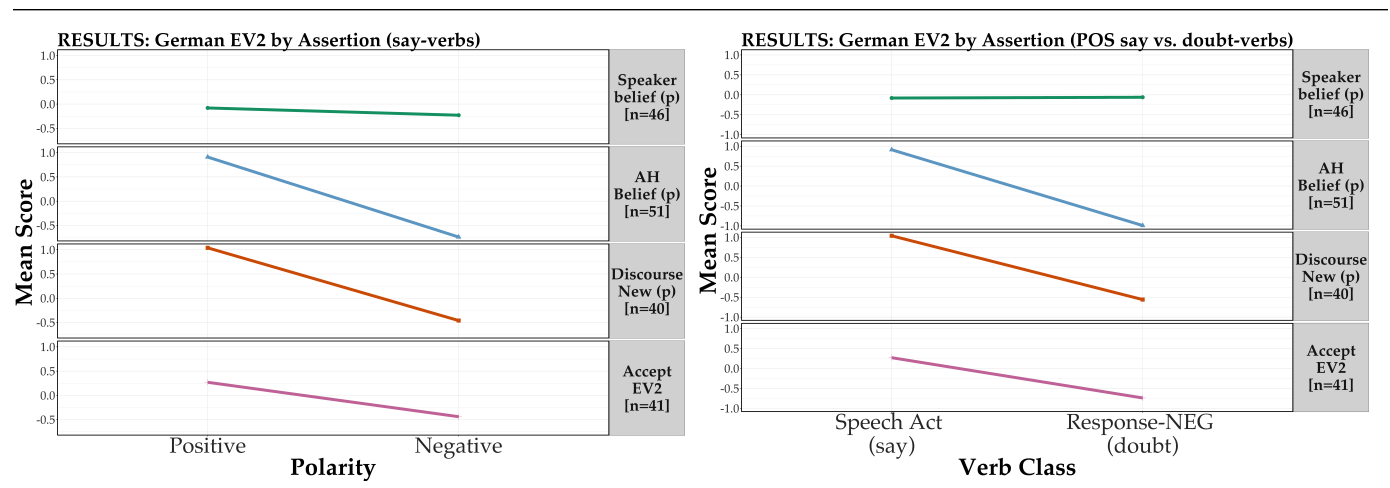

Figure 1 Predictions, and results, for German embedded V2 based on the responses for the three dimensions of assertion: effect of negation.

captured by the variation in the unmarked control version) were then bound to the data and used as the new dependent variable for each MCP. This allowed us to rule out a interpretation of the results whereby what might look like a given MCP being assigned low ratings in a particular embedded context, is in fact just the product of a general degradation of any sentence occurring in this context.

\subsection{Analysis}

The data was analysed with linear mixed-effects models (using lmer from the lme4 package in R), predicting acceptability and pragmatic inference scores from the identity and type of predicate, polarity, and their interaction (for further models and discussion, see Djärv 2019b). The filler and control conditions were excluded from the statistical analysis. Subject and item were included in the random effects for all models. In the models based on verb class, the positive speech act predicates were used as the intercept, and for those based on the verb, say was the intercept.

\subsection{Results}

As we discussed in relation to (10) above, (attitude holder) commitment-based and discourse novelty-based assertion accounts make the same predictions for verbs like say and think (which permits both commitment and novelty) vs. not say, not think and doubt, deny (which disallow both commitment and novelty). ${ }^{9}$

Looking at the responses for these conditions in German (Figure 1), we find that, in line with the intuitions reported in (10), both the responses for attitude holder commitment to $\mathrm{p}$ and those for $\mathrm{p}$ as discourse new information predict that say and

9 Given the size and scope of this study, we focus here on some of its core findings. 


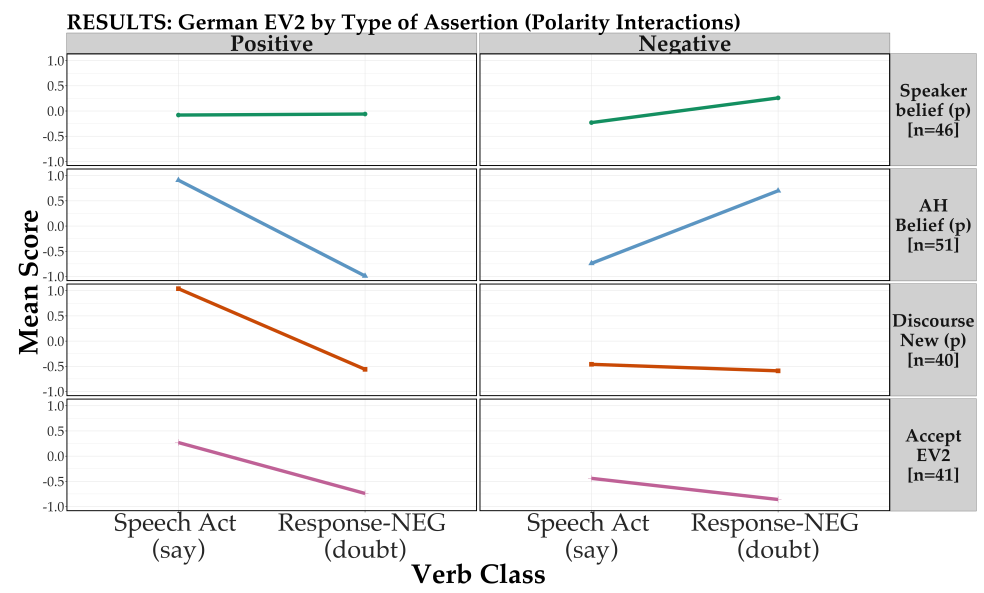

Figure 2 Predictions, and results, for German embedded V2 based on the responses for the three dimensions of assertion: interaction with negation.

other Speech Act verbs (see Table 2 in the Appendix) should allow embedded V2 -by virtue of making available a reading where $\mathrm{p}$ is 'asserted'. Under negation, however (e.g. not say) neither account predicts that embedded V2 should be available, given that these contexts do not license 'embedded assertions' in either sense (left graph). The exact same predictions are made for the negative response verbs like doubt and deny (right graph). Accounts based purely on speaker-commitment, on the other hand, are found to predict no differences across these conditions. As Figure 1 further illustrates, the predictions of attitude holder commitment and discourse novelty are both borne out for embedded V2; as we would expect given (10). (The $\mathrm{y}$-axis represent average (z-scored; and for embedded V2, residualized) scores for each measures, across the four verbs of each conditions, and across participants and items.)

As conjectured above, and discussed in the context of (15), the predictions of the two assertion-based accounts come apart, however, when we look at the interaction of these predicates with negation. Figure 2 shows that attitude holder commitment to $\mathrm{p}$ predicts that embedded V2 should be available under not doubt and not deny, in line with (15) above. Discourse novelty, on the other hand, predicts that embedded V2 should be unavailable, regardless of the polarity of the verb. Here, we find that it is only the predictions of the discourse novelty-based account that are borne out in the acceptability scores for embedded V2, contrary to Wiklund (2010).

Turning to the role of factivity, Figure 3 shows that the distribution of embedded $\mathrm{V} 2$ across the two types of factives is exactly in line with the judgements reported by Hooper \& Thompson (1973): V2 is available under cognitive but not emotive 


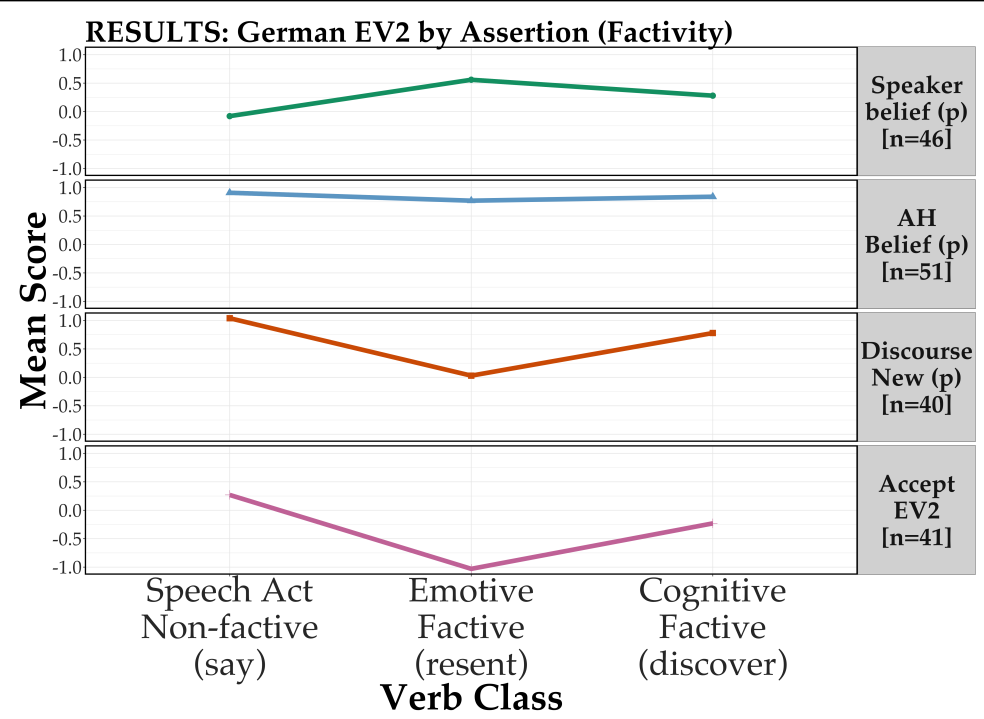

Figure 3 Predictions, and results, for German embedded V2 based on the responses for the three dimensions of assertion: factivity.

factives; again, as we find to be predicted by the discourse novelty-based account.

Statistically, all verb classes except the doxastic non-factives (e.g. believe) differ significantly from the speech act verbs (p's $<0.005)$. In the case of the cognitive factives, however, the effect size is small $(\beta=-0.51)$ relative to that of the emotive factives $(\beta=-1.3)$ and the negative response verbs $(\beta=-1.01)$. The positive response verbs show an intermediate effect size $(\beta=-0.7)$. We also observe a main effect of negation $(\beta=-0.71, \mathrm{p}<0.005)$, as well as a significant interaction with negation in all cases except the doxastic factives (p's $<0.05$ ). For the doxastic non-factives, this interaction was driven by the fact that these are rated slightly higher in the positive condition $(\beta=0.24)$, an effect that was not significant. In the other cases, the interaction was driven by the low scores in the positive polarity. In other words, the only conditions which show high acceptability scores for embedded V2 were the speech act verbs (e.g. say), the doxastic non-factives (e.g. believe), and the cognitive factives (e.g. discover); but only in the positive polarity.

Turning briefly to the other MCP investigated, these were found to show no sensitivity to either of the pragmatic or lexical factors investigated here. While there were certain contrasts that come out as significant, all effect sizes were relatively small, and in neither case did they track any of the predictions made by any of the various theoretical accounts; for instance, each of the speech act adverbs, the scene setting adverbs, and topicalization were rated higher under negative response verbs such as doubt in both English discourse conditions $(\beta<-0.5$, p's $<0.005)$. (See 


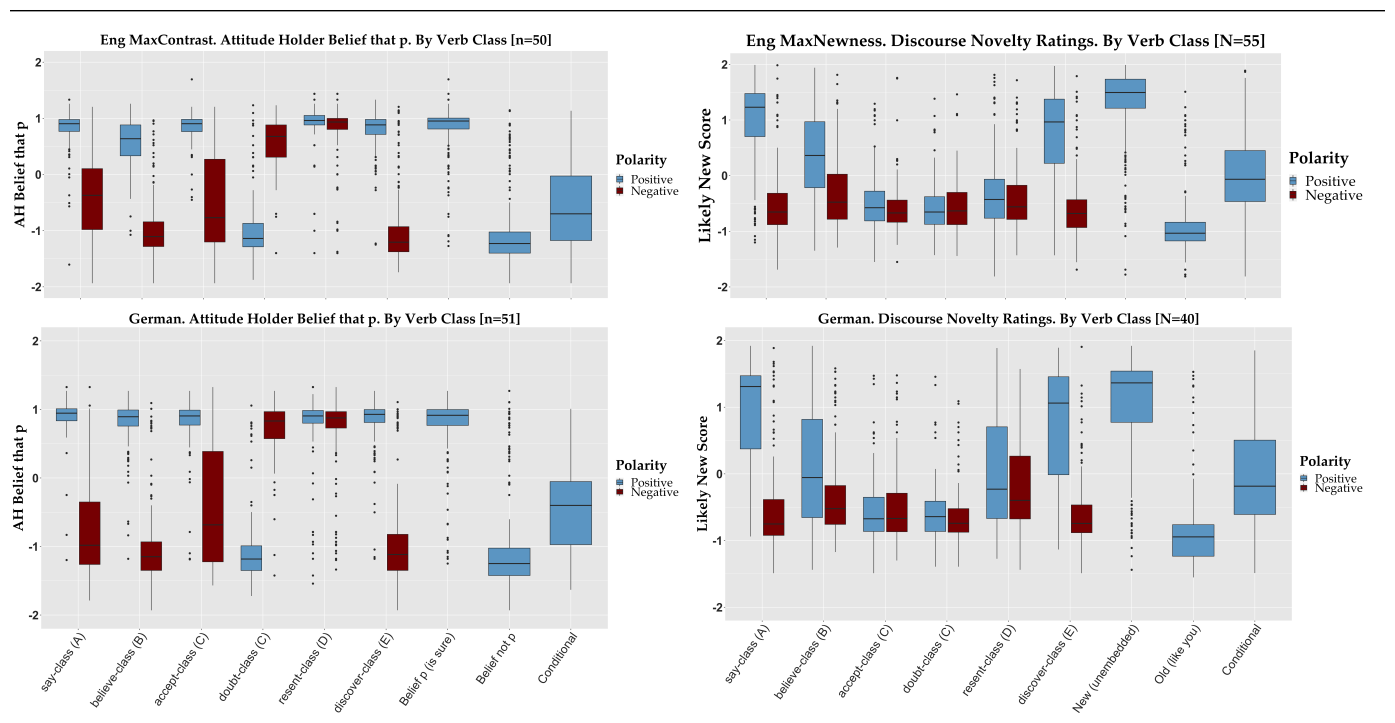

Figure 4 Left: Scores for attitude holder commitment to p. Right: Scores for $\mathrm{p}$ as discourse new information: Top: English. Bottom: German.

Figure 11 in the Appendix.)

We further raised the possibility above that conflicting judgements might be due to differences in the pragmatic properties associated with the various verb classes across languages. However, as illustrated in Figure 4, the pragmatics associated with the different embedding contexts were found to be remarkably stable and robust across the different languages; thus motivating the use of these classes as theoretically meaningful constructions.

Looking at the responses by-participant also suggests that conflicting judgements are likely not the product of significant inter-speaker variation (see Figure 12 in the Appendix).

\section{Discussion}

From the pragmatic inference studies, we were able to derive empirically motivated estimates of the various pragmatic dimensions claimed to be responsible for MCP licensing, independently of the embedding predicate. For the exact same items, we then derived acceptability for the various MCP. This way, we were able to disentangle the various pragmatic and lexical accounts of MCP-licensing.

Interestingly, and somewhat surprisingly, we saw that among the four types of MCP investigated here, only embedded V2 showed any sensitivity to any of the lexical or pragmatic factors investigated. The pattern we found was very similar to that observed for Swedish V2 in quantitative studies by Caplan \& Djärv (2019) and 
Djärv, Heycock \& Rohde (2017), as well as for Danish V2 in Jensen \& Christensen 2013: V2 was rated as acceptable, only under the speech act verbs, the doxastic non-factives, and the doxastic factives (in line with (13)). Additionally, we found all of these predicate types to license V2 only in the positive polarity; thus replicating, and further extending, the findings of Caplan \& Djärv (2019). The large effect of negation speaks strongly against a selection-based account. Rather, the acceptability of $\mathrm{V} 2$ is predicted by the interpretation of $\mathrm{p}$ as discourse new information, in line with the pragmatic approach of Caplan \& Djärv (2019). The pragmatic accounts based on speaker and attitude holder commitment to $\mathrm{p}$, however, were found to over-generate the kinds of contexts that are predicted to allow embedded V2.

It is remarkable, that only embedded V2 was found to show the distribution of MCP described by Hooper \& Thompson (1973), given that their discussion was based entirely on English. In another sense, however, it is perhaps not too surprising, given the vast disagreements in the theoretical literature about the nature of the data. This raises the question of what (if anything) a comprehensive theory of MCP should look like. We leave this issue for the time being (though see discussion in Djärv 2019 b); focusing instead on the implications of our findings for embedded V2 and the discourse novelty ratings; in particular, what they mean for our understanding of factivity and the grammatical expression of ASSERTION.

First, let us consider what specific notion of discourse novelty is relevant to the grammar. The relevant notion cannot be that $\mathrm{p}$ is Common Ground, as shown most clearly by predicates like doubt or don't think. As the experimental results showed us, these predicates do require that $\mathrm{p}$ has some kind of antecedent. However, while (16) would be infelicitous in a context where the issue of ?p (Will John and Bill get along?) has not previously been discussed, it is clear that the speaker is not committed to $\mathrm{p}$ here; hence, $\mathrm{p}$ is not Common Ground.

a. I doubt that $\left[{ }_{P}\right.$ John and Bill will get along].

b. I don't think that [ $P$ John and Bill will get along].

Rather, what's important is simply that $\mathrm{p}$ has some kind of antecedent in the discourse context. Importantly, while the response predicates and the emotive factives both share this general property, they differ in whether this antecedent has to be linguistic or not. As we argue in more detail in Djärv 2019b: Ch. 5, the emotives require simply that the attitude holder's belief that $\mathrm{p}$, and the source of this belief, ${ }^{10}$ can be plausibly inferred from the context. The response predicates, on the other hand, require an actual linguistic antecedent, such that $\mathrm{p}$ has either been proffered, or that the question of ?p has bee raised: this contrast is illustrated in (17):

10 We link this anaphoric presupposition, a stronger form of definiteness (Schwarz 2009), to the presence of a D-layer. 
(17) [Mary and Bill are lying on the beach on a beautiful sunny day. Not having previously discussed the weather, Mary says:]

I'm so happy that it turned out to be such a nice day!

\#I \{doubt, didn't say\} that it's going to rain later.

The relevant pragmatic dimension relevant to embedded V2, then, seems to be very similar to Schwarzschild's (1999) notion of Givenness; whereby p must have some kind of 'antecedent'; broadly taken to encompass both overt linguistic antecedents, as well as accommodated or contextually entailed antecedents.

Note, however, that this claim seems to be compatible with the presuppositionbased accounts discussed above (Kiparsky \& Kiparsky 1970 et seq), according to which 'presuppositional' predicates select for complements that are syntactically DPs, and semantically and pragmatically presupposed - only with the revised empirical position that the cognitive factives are not 'presuppositional'. However, the interaction with negation is problematic for this view: even if verbs like doubt and resent select for DPs, which effectively block embedded V2, we would still need an explanation for the ban on V2 and discourse novelty with negated verbs like say and think. One might be tempted to propose that in these contexts, DP-complements are 'pragmatically licensed'. However, this hypothesis cannot be right. As shown by (19), neither the response predicates, nor predicates like don't think impose a general ban on CPs (see Moulton 2015, and Djärv 2019b: Sec. 2.3 for further discussion): ${ }^{11}$

a. I know you think that we should leave, but I certainly don't think so.

b. You're clearly not going to win! / Yes, so I've come to accept.

Hence, the fact that these contexts disallow embedded V2 cannot be explained by appealing to the presence of a D-layer. Rather, the empirical picture aligns with the assertion-based view, according to which the contexts that allow V-to-C movement are distinguished syntactically in terms of the type of the embedded CP.

Interestingly, as discussed in greater detail in Djärv 2019b: Ch. 2, the availability of $w$-extraction in English turns out to track the distribution of embedded V2 and discourse novelty across predicate types, as shown in (20) (contrary to much work on ‘factive islands'; e.g. Rizzi 1990; Cinque 1991; Rooryck 1992; Szabolcsi \& Zwarts 1993; Abrusán 2011; Schwarz \& Simonenko 2018).

11 This diagnostic is based on distributional evidence, showing that so is a CP and not a DP-anaphor:

a. It seems $[C P\{$ so, that John left $\}]$.

b. *It seems $[D P$ \{that, it, the fact that John left, John's leaving $\}]$. 
The Syntax of Assertion and Presupposition

a. $\mathrm{Who}_{i}$ did you notice $\mathrm{t}_{i}$ left their backpack after school? ${ }^{12}$

b. $\mathrm{Who}_{i}$ did he know for sure $\mathrm{t}_{i}$ stole the cookies?

c. $* \mathrm{Who}_{i}$ did he fiercely deny/firmly resent $\mathrm{t}_{i}$ stole the cookies?

This observation, then, is in line with the idea, going back to Weerman, de Haan, Haider \& Prinzhorn (1986); Iatridou \& Kroch (1992) and Vikner (1995) (see also recent work by Featherston 2004), that V2 is licensed in the complements of socalled bridge verbs. From this observation, we hypothesize that the position required for $w h$-extraction in English is the same as that involved in $\mathrm{V}$-to-C movement in Swedish and German; a position which is licensed by ASSERTION, in the sense that $\mathrm{p}$ is discourse new information (in contrast to Given).

Finally, we have seen that, contrary to the traditional conception of factivity (following Stalnaker 1974), it is not the case that factives in general require $\mathrm{p}$ to be Common Ground, or Given. In fact, the doxastic factives were found to promote a reading of $\mathrm{p}$ as discourse new. The question then is where this leaves our theory of factivity, which analyses factive verbs as verbs which require that $\mathrm{p}$ is Common Ground (thus entailing that $\mathrm{p}$ is Given, in a strong sense) - an idea which have seen cannot be maintained. In Djärv 2019b: Ch. 5, we propose a solution to this puzzle: decomposing the classically multifaceted notion of factivity into a set of more specific, and explanatory, theoretical notions; importantly, dissociating the source of the discourse status of $p$ and the source of the projective inference that the speaker takes $\mathrm{p}$ to be true (the 'factive' inference). Unfortunately, reasons of space prevent a full discussion of this account, and its connection to the current results, but the key innovation is the analysis of the projective, factive, inference as stemming from a presupposition of an evidential modal base that entails $p$, rather than a presupposition of $\mathrm{p}$ itself, thus eliminating the consequence of the Common Ground analysis that the two dimensions should go hand-in-hand.

\section{Concluding remarks}

Assertion is often argued to provide the semantic-pragmatic underpinning of various complementation patterns, including MCP. Here, we have presented new experimental data allowing us to make these notions more precise: first, the dimension of ASSERTION relevant to the licensing of embedded V2 is the discourse status of $p$ as new vs. Given (in the sense of Schwarzschild 1999); a dimension which cross-cuts both factive and non-factive verbs. However, it's not the case that discourse novelty simply makes available the kind of complement that licenses any type of MCP: the other MCP investigated showed no sensitivity to either of the lexical or pragmatic factors. We further showed that Givenness is not encoded in a D-layer.

12 Thanks Julie Anne Legate, and Luke Adamson, p.c., for these judgements. 


\section{References}

Abrusán, Márta. 2011. Presuppositional and negative islands: A semantic account. Natural Language Semantics 19(3). 257-321.

Basse, Galen. 2008. Factive complements as defective phases. In Natasha Abner \& Jason Bishop (eds.), The 27th West Coast Conference on Formal Linguistics, 54-62. Somerville, MA, USA: Cascadilla Proceedings Project.

Bianchi, Valentina \& Mara Frascarelli. 2009. Is topic a root phenomenon? Published on LingBuzz.

Caplan, Spencer \& Kajsa Djärv. 2019. What usage can tell us about grammar: Embedded Verb Second in Scandinavian. Glossa: a journal of general linguistics 4(1). 1-37.

Cinque, Guglielmo. 1991. Types of A'-Dependencies. Cambridge, MA: MIT Press.

De Cuba, Carlos. 2017. Noun complement clauses as referential modifiers. Glossa: a journal of general linguistics 2(1).

De Cuba, Carlos \& Barbara Ürögdi. 2010. Clearing up the 'Facts' on Complementation. In Jon Scott Stevens (ed.), University of Pennsylvania Working Papers in Linguistics, vol. 161 , .

Djärv, Kajsa. 2019a. Assertion and Presuppositions in Attitude Reports and Main Clause Syntax. doi:10.17605/OSF.IO/NSM89. https://osf.io/nsm89/.

Djärv, Kajsa. 2019b. Factive and Assertive Attitude Reports: The University of Pennsylvania $\mathrm{PhD}$ dissertation.

Djärv, Kajsa, Caroline Heycock \& Hannah Rohde. 2017. Assertion and factivity: Towards explaining restrictions on Embedded V2 in Scandinavian. In Laura Bailey \& Michelle Sheehan (eds.), Order and Structure in Syntax (Open Generative Syntax), 1-31. Language Science Press.

Featherston, Sam. 2004. Bridge verbs and V2 verbs: The same thing in spades? Zeitschrift für Sprachwissenschaft 23(2). 181-210.

Haegeman, Liliane. 2012. The syntax of MCP: Deriving the truncation account. Main clause phenomena: New horizons 190. 113-134.

Haegeman, Liliane. 2014. Locality and the distribution of Main Clause Phenomena. In Enoch Oladé Aboh, Maria Teresa Guasti \& Ian Roberts (eds.), Locality (Oxford Studies in Comparative Syntax), 186-222. Oxford: Oxford University Press.

Haegeman, Liliane \& Barbara Ürögdi. 2010. Referential CPs and DPs: An operator movement account. Theoretical Linguistics 36. 111-152.

Hegarty, Michael. 1992. Adjunct extraction without traces. In Dawn Bates (ed.), The 10th West Coast Conference on Formal Linguistics, 209-222. Stanford: CSLI Publications.

Heim, Irene. 1982. The semantics of definite and indefinite NPs: University of 
The Syntax of Assertion and Presupposition

Massachusetts at Amherst PhD dissertation.

Heim, Irene. 1983. On the projection problem for presuppositions. In Daniel P. Flickinger (ed.), The 2nd West Coast Conference on Formal Linguistics, 114125. Stanford University, Stanford, California: CSLI Publications.

Hooper, Joan \& Sandra Thompson. 1973. On the applicability of root transformations. Linguistic Inquiry 4.4. 465-497.

Iatridou, Sabine \& Anthony Kroch. 1992. The licensing of CP-recursion and its relevance to the Germanic verb-second phenomenon. In Working Papers in Scandinavian Syntax, Citeseer.

Jensen, Torben Juel \& Tanya Karoli Christensen. 2013. Promoting the demoted: The distribution and semantics of "main clause word order" in spoken Danish complement clauses. Lingua 137. 38-58.

Julien, Marit. 2015. The force of V2 revisited. The Journal of Comparative Germanic Linguistics 18(2). 139-181.

Kastner, Itamar. 2015. Factivity mirrors interpretation: The selectional requirements of presuppositional verbs. Lingua 164. 156-188.

Kiparsky, Paul \& Carol Kiparsky. 1970. Fact. In Michael Bierwisch \& Karl Erich Heidolph (eds.), Progress in Linguistics, 143-173. The Hague: Mouton.

Maki, Hideki, Lizanne Kaiser \& Masao Ochi. 1999. Embedded topicalization in English and Japanese. Lingua 109. 1-14.

Moulton, Keir. 2015. CPs: Copies and compositionality. Linguistic Inquiry 46(2). 305-342.

Rizzi, Luigi. 1990. Relativized minimality. Cambridge, MA: MIT Press.

Rizzi, Luigi. 1997. The fine structure of the left periphery. In Elements of grammar Kluwer International Handbooks of Linguistics, 281-337. New York: Springer.

Rooryck, Johan. 1992. Negative and factive islands revisited. Journal of Linguistics 28. 343-374.

Schwarz, Bernhard \& Alexandra Simonenko. 2018. Factive islands and meaningdriven unacceptability. Natural Language Semantics 26(3-4). 253-279.

Schwarz, Florian. 2009. Two kinds of definites cross-linguistically.: University of Massachusetts at Amherst PhD dissertation.

Schwarzschild, Roger. 1999. GIVENness, AvoidF and other constraints on the placement of accent. Natural language semantics 7(2). 141-177.

Schütze, Carson T. \& Jon Sprouse. 2014. Judgment data. In Robert J. Podesva \& Devyani Sharma (eds.), Research Methods in Linguistics, 27-50. Cambridge, UK: Cambridge University Press.

Simons, Mandy. 2007. Observations on embedding verbs, evidentiality, and presupposition. Lingua 117. 1034-1056.

Stalnaker, Robert. 1974. Pragmatic presuppositions. In Semantics and philosophy, 197-213. New York: New York University Press. 
Stalnaker, Robert. 1978. Assertion. In Syntax and semantics, vol. 9, 315-322. Academic Press.

Szabolcsi, Anna \& Frans Zwarts. 1993. Weak islands and an algebraic semantics for scope taking. Natural language semantics 1(3). 235-284.

Truckenbrodt, Hubert. 2006. On the semantic motivation of syntactic verb movement to $\mathrm{C}$ in German. Theoretical Linguistics 32(3). 257-306.

Vikner, Sten. 1995. Verb movement and expletive subjects in the Germanic languages. Oxford University Press.

Weerman, FP, G de Haan, H Haider \& M Prinzhorn. 1986. Finiteness and Verb Fronting in Frisian. Publications in language sciences (21).

Wiklund, Anna-Lena. 2010. In search of the force of dependent verb second. Nordic Journal of Lingusitics 33(1). 81-91.

Wiklund, Anna-Lena, Kristine Bentzen, Gunnar Hrafn Hrafnbjargarson \& Porbjörg Hróarsdóttir. 2009. On the distribution and illocution of V2 in Scandinavian that-clauses. Lingua 119(12). 1914-1938.

Woods, Rebecca. 2016. Investigating the syntax of speech acts: embedding illocutionary force: University of York PhD dissertation.

Zehr, Jérémy \& Florian Schwarz. 2018. PennController for Internet Based Experiments (IBEX). doi:10.17605/OSF.IO/MD832. https://osf.io/md832/.

Kajsa Djärv

Department of Linguistics

Universität Konstanz

78457 Konstanz

Germany

kajsa.djarv@uni-konstanz.de 
The Syntax of Assertion and Presupposition

\section{Appendices}

\begin{tabular}{l||l|l|l}
\hline \hline Verb Class & English & German & Swedish \\
\hline \hline \multirow{5}{*}{ Speech Act Verbs (A) } & say & sagen & säga \\
& mention & erwähnen & nämna \\
tell me & mir erzählen & berätta \\
& claim & behaupten & hävda \\
\hline \multirow{5}{*}{ Doxastic Non-factives (B) } & believe & glauben & tro \\
& assume & annehmen & anta \\
& reckon & meinen & förmoda \\
& guess/suppose & vermuten & gissa \\
\hline \multirow{5}{*}{ Response verbs (C) } & accept & akzeptieren & acceptera \\
& admit & zugeben & erkänna \\
& doubt & bezweifeln & vivla \\
Emörneka
\end{tabular}

Table 2 Verbs and verb classes manipulated in the experiment. The letters in parenthesis represent the names assigned to each class in Hooper \& Thompson's classic 1973-paper, and which are commonly used in the MCP literature as a short-hand for the different classes. 
Imagine that you're at a party, and you overhear part of a conversation between your friends, Bill and Jack.

Jack says:

...however, Anne says that Lisa broke up with the guy she's been dating!

Figure 5 Discourse Condition 2: Maximize Contrast [ MAXCONTRAST]

Two friends, Bill and Jack, run into each other.

Jack says:

Guess what! I just talked to Anne, and she says that Lisa broke up with the guy she's been dating!

Figure 6 Discourse Condition 2: Maximize Newness (MAXNEWNESS) 
The Syntax of Assertion and Presupposition

Please read the instructions carefully before you continue!

In this experiment you will be presented with short scenarios, like those illustrated below:

Imagine that you're at a party, and you overhear part of a conversation between two of your friends:

...however, John said that Lisa decided to break up with the guy she's been dating!

You will then be asked to complete a statement, of the type illustrated below, about the sentence you just saw:

To me, this sentence sounds:

Completely unnatural $\bigcirc \bigcirc \bigcirc \bigcirc \bigcirc$

Note that there is no right and no wrong answer. Simply choose the answer that you prefer.

\section{Figure 7 Task Instructions (MAXCONTRAST)}

Imagine that you're at a party, and you overhear part of a conversation between your friends, Sally and Rory.

Rory says:

... however, Sophia maintains that Tammy doesn't like the landlady.

As far as Sophia is concerned, Tammy doesn't like the landlady.

No $\bigcirc 00000000$ Yes

Maybe

Figure 8 Attitude holder commitment, task (MAXCONTRAST) 
Imagine that you're at a party, and you overhear part of a conversation between your friends, Sally and Rory.

Sally says:

... however, Sophia maintains that Tammy doesn't like the landlady.

As far as Sally is concerned, Tammy doesn't like the landlady.
No $\bigcirc \bigcirc \bigcirc \bigcirc \bigcirc \bigcirc \bigcirc \bigcirc$ Yes
Maybe

Figure 9 Speaker commitment, task (MAXCONTRAST)

Imagine that you're at a party, and you overhear part of a conversation between your friends, Sally and Rory.

Sally says:

... however, Sophia maintains that Tammy doesn't like the landlady.

It is likely

that Sally and Rory have previously talked about Tammy not liking the landlady.

Figure 10 Discourse novelty, task (MAXCONTRAST) 
The Syntax of Assertion and Presupposition

\begin{tabular}{|c|c|c|c|c|}
\hline Language & Measure & $\mathrm{N}$ pre-exclusion & $\mathrm{N}$ removed & $\mathrm{N}$ post-exclusion \\
\hline \multirow{8}{*}{$\begin{array}{l}\text { English } \\
\text { MAXNEW }\end{array}$} & Unm & 55 & 6 & 49 \\
\hline & Top & 63 & 5 & 58 \\
\hline & Scene.Adv & 77 & 4 & 73 \\
\hline & SpAct.Adv & 50 & 7 & 43 \\
\hline & AHbel & 61 & 2 & 59 \\
\hline & SpBel & 61 & 1 & 60 \\
\hline & DiscNew & 61 & 6 & 55 \\
\hline & Total N & 428 & 31 & 397 \\
\hline \multirow{8}{*}{$\begin{array}{l}\text { English } \\
\text { MAXCONTR }\end{array}$} & Unm & 56 & 4 & 52 \\
\hline & Top & 62 & 16 & 46 \\
\hline & Scene.Adv & 62 & 7 & 55 \\
\hline & SpAct.Adv & 58 & 4 & 54 \\
\hline & AHbel & 53 & 3 & 50 \\
\hline & SpBel & 61 & 4 & 57 \\
\hline & DiscNew & 65 & 10 & 55 \\
\hline & Total N & 417 & 48 & 369 \\
\hline \multirow{7}{*}{ German } & Unm & 48 & 1 & 47 \\
\hline & SpAct.Adv & 50 & 2 & 48 \\
\hline & V2 & 44 & 3 & 41 \\
\hline & AHbel & 51 & 0 & 51 \\
\hline & SpBel & 47 & 1 & 46 \\
\hline & DiscNew & 45 & 5 & 40 \\
\hline & Total N & 285 & 12 & 273 \\
\hline \multirow{7}{*}{ Swedish } & Unm & 34 & 5 & 29 \\
\hline & SpAct.Adv & 20 & 7 & 13 \\
\hline & V2 & 33 & 12 & 21 \\
\hline & AHbel & 14 & 0 & 14 \\
\hline & SpBel & 24 & 1 & 23 \\
\hline & DiscNew & 17 & 1 & 16 \\
\hline & Grand Total N & 142 & 26 & 116 \\
\hline \multicolumn{2}{|c|}{ Total N } & 1,272 & 117 & 1,155 \\
\hline
\end{tabular}

Table 3 Number of participants, and outliers removed, by between-participant condition. 

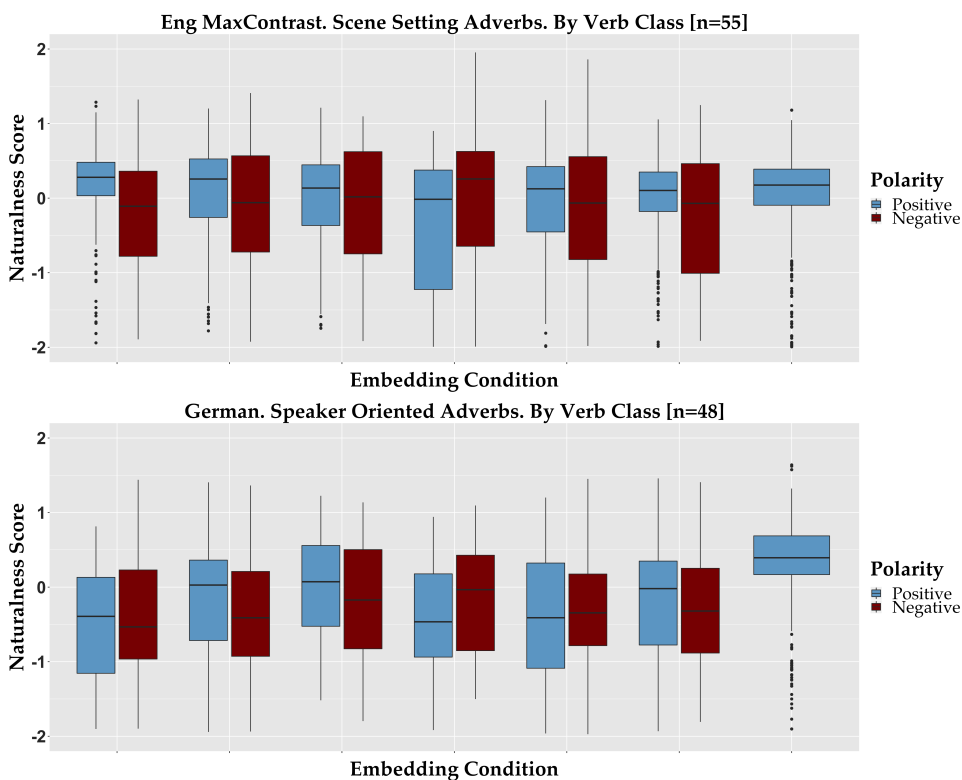

Polarity

音 Positive

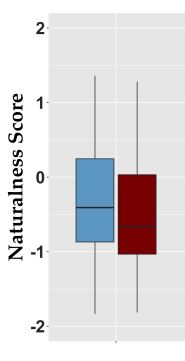

Eng MaxContrast. Topicalization. By Verb Class [n=46]
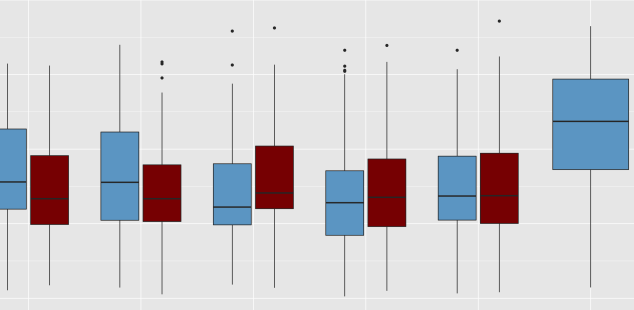

Polarity

音 Positive

Embedding Condition

German. V2. By Verb Class [n=41]
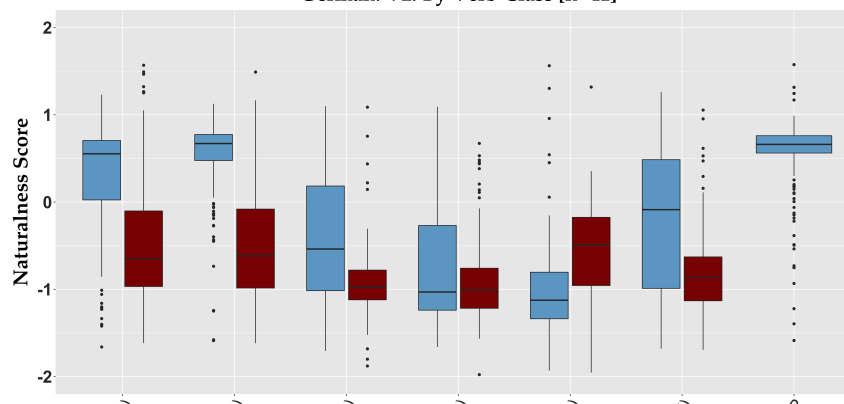

Polarity

自 Positive

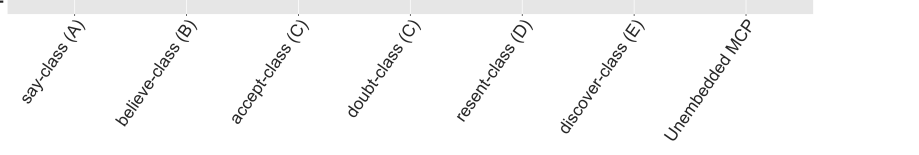

Embedding Condition

Figure 11 Top to bottom: scene setting adverbs (English); speech act adverbs (German); topicalization (English); embedded V2 (German). Distribution across all embedding conditions. 
The Syntax of Assertion and Presupposition

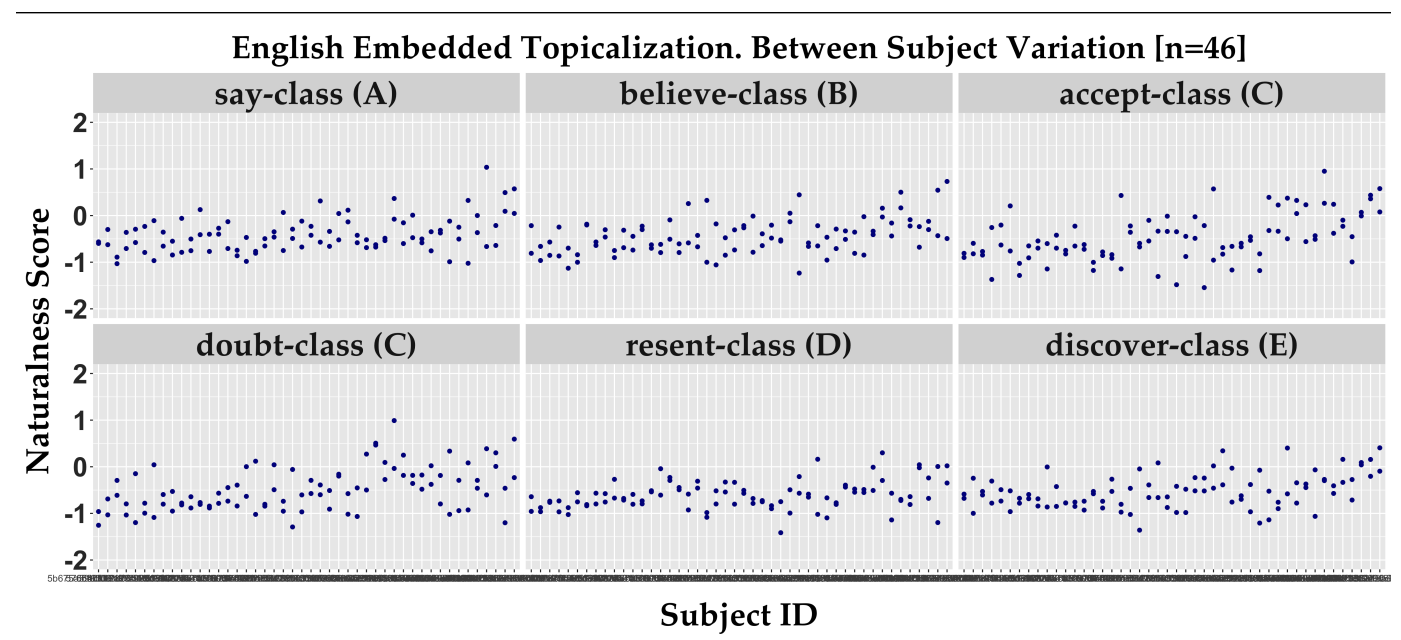

Figure 12 By participant acceptability ratings for English embedded topicalization. 